\title{
AS MANIFESTAÇÕES BRASILEIRAS DE JUNHO DE 2013 E SUAS IMPLICAÇÕES JURÍDICO-POLÍTICAS
}

\author{
THE BRAZILIAN DEMONSTRATIONS OF JUNE 2013 AND THEIR LEGAL-POLITICAL \\ IMPLICATIONS
}

Vinicius Azevedo Coelho*

\begin{abstract}
Resumo:
\end{abstract}
Este artigo realiza um estudo das manifestações ocorridas no Brasil, em junho de 2013. O objetivo é explorar relações entre movimentos sociais e direitos, e consequentemente investigar implicações causadas pelas manifestações nos sistemas jurídico e político brasileiros. Parte-se da hipótese de que movimentos sociais, no contexto de complexidade da sociedade contemporânea, provocam irritações no ambiente do direito e da política, que processam ou não as expectativas dos manifestantes. Se não indiferentes, os sistemas podem reagir nas formas de conservação ou mudança. Para ilustrar essa hipótese, três eventos destacados das jornadas de junho são sequencialmente analisados: (i) demanda pelo direito de transporte; (ii) repressão ao direito de manifestação; (iii) discussão sobre projetos de alteração legislativa PEC n. 37/2011 e PDC n. 234/2011. Os resultados desta investigação sugerem que as manifestações, a princípio rejeitadas, produziram mudanças jurídicas e políticas, evidenciadas pela revogação do aumento nas tarifas do transporte e pelo arquivamento dos projetos legislativos.

Palavras-chave: Manifestações de junho de 2013. Movimentos Sociais. Teoria dos Sistemas.

\begin{abstract}
:
This research performs a study of the protests in June 2013 in Brazil. The aim is to explore the relations between social movements, law and politics and, consequently, investigate the possible implications caused by June 2013 protests in the Brazilian legal and political systems. In the context of complexity and contingency of contemporary society, the initial hypothesis is that social movements produce annoyance in the environment of functional systems, which process or not the protestors' expectations. If not indifferent, the systems can react to claims through conservation (rejection) or change (acceptance). In order to empirically test the hypothesis raised, three socio-legal events highlighted during the protests in June are sequentially analyzed: (i) the demand for the right to public transportation; (ii) the repression to the right to protests and (iii) public discussion around the constitutional amendment projects (37/2011) and Legislative Decree (234/2011). The results of this investigation suggest that the demonstrations in June 2013, initially repressed by functional systems, were able to produce practical effects on law and politics, which were evidenced by the revocation of the increase in public transport fares and
\end{abstract}

\footnotetext{
Advogado. Mestre em Direito pela Universidade de São Paulo. Atualmente é Doutorando em Direito pela Universidade de São Paulo. Desenvolve pesquisas relacionadas a movimentos sociais, direito e internet. E-mail: viniciusazevedocoelho@gmail.com.
} 
the archiving of projects able to change rules within the constitutional framework.

Keywords: June demonstrations in Brazil. Social Movements. Systems Theory.

Introdução

Este artigo consiste em um estudo das manifestações de junho de 2013, no Brasil, e de suas reivindicações por direitos, inspirado no arcabouço conceitual oferecido pela Teoria dos Sistemas Sociais, na redescrição de Niklas Luhmann.

As manifestações de junho de 2013 são entendidas como legítimo movimento social, e compreendidas enquanto contextos comunicativos conectados aos sistemas de modo específico: são movimentos que buscam irritar os sistemas funcionais, que, se não indiferentes, podem responder por meio de fórmulas que produzem variações entre conservação (rejeição) e mudança (aceitação). Essas três possibilidades (indiferença, conservação e mudança) consistem na hipótese teórica a ser empiricamente verificada.

Para a Teoria dos Sistemas, a sociedade é entendida como um sistema que abarca, em seu interior, diversos subsistemas, que se diferenciam cada qual por sua função, como o direito, a política, a economia etc. Cada sistema se define por suas diferenças em relação ao seu ambiente, e contém em si o necessário para desenvolver suas operações. Apesar de operativamente fechados, eles mantêm canais para comunicação com seu entorno, o que permite, sob determinadas condições, que um sistema seja influenciado por provocações externas, provenientes do ambiente. Nessas provocações que residem propostas de movimentos sociais: tentam produzir irritações para fazer mudar internamente o sentido comunicacional dos sistemas. Assim, inconsistências e perversões do funcionamento dos sistemas tornam-se alvos para críticas dos movimentos sociais.

Os sistemas de maior relevância para este estudo são o direito e a política. Ambos são tratados como instâncias receptivas aos movimentos sociais, que pretendem introduzir novas diferenças na comunicação, possibilitando novos horizontes temáticos para aplicação ou reconhecimento de direitos.

Para ilustrar empiricamente as posições adotadas pelo direito e pela política diante das manifestações de junho, foram selecionados três eventos sociojurídicos: (i) a revogação do aumento das tarifas de transporte público; (ii) a repressão ao direito de manifestação e (iii) os projetos de âmbito nacional PEC n. 37/2011 e PDC n. 234/2011. Esses eventos se relacionam de forma sequencial: a reivindicação pelo transporte é seguida pela repressão, com a consequente expansão dos atos em razão da veiculação midiática da violência policial, outras demandas passam a integrar a pauta das manifestações, como o arquivamento dos projetos de alteração de leis de âmbito constitucional, PEC n. 37 e PDC n. 234 de 2011. O intuito é recorrer a esses eventos para testar a hipótese teórica levantada, 
qual seja, de que movimentos sociais provocam irritação nos sistemas na expectativa de estimulá-los a operacionalizar mudanças relacionadas a direitos.

1. Inclusão e exclusão: o papel e a contribuição dos movimentos sociais

Em junho de 2013, manifestações ocorreram em todos os estados brasileiros. Milhões de pessoas saíram às ruas para protestar pelo direito de transporte, direito de manifestação e por outras reivindicações pontuais, como arquivamento da PEC n. 37/2011, denominada de "PEC da impunidade", e do PDC n. 234/2011, apelidado de "cura gay".

Para compreender esse acontecimento e verificar suas implicações jurídicopolíticas, é preciso investigar os motivos e o sentido que os próprios manifestantes atribuíram aos acontecimentos para transformá-los em movimento de massa.

A sociedade experimenta uma necessidade de se queixar contra $o$ que não tem sentido (LUHMANN, 2011b, p. 249). Movimentos sociais tentam provocar alteração interna no sistema-alvo de seus protestos, para que, assim, o sistema em questão atualize o sentido de suas comunicações. A negação ou a restrição de direitos pode gerar inquietação, que pode ser condensada na forma de movimento social. A indignação é transformada na indicação de um problema a ser tratado pelo sistema provocado.

Em um contexto como o brasileiro, muitas vezes marcado pela exclusão social, os movimentos sociais podem representar o protesto daqueles que se encontram excluídos ou, conforme Luhmann (1996, p. 183), também daqueles que se sensibilizam com a condição de exclusão que recai sobre outros.

A pretensão universalista do sistema jurídico de incluir a todos revela um paradoxo. Nem todos têm seus direitos reconhecidos, ou podem usufruir desses direitos (CAMPILONGO, 2012, p. 50-51). A exclusão é uma característica marcante da sociedade diferenciada funcionalmente (LUHMANN, 1998). É contra a exclusão e as estruturas que a desenvolvem que os movimentos sociais se posicionam e se organizam.

Em 2013, muitos desapontamentos faziam parte do cotidiano do brasileiro. Além da causa do transporte, outras reivindicações acabaram por converter-se, no decorrer dos protestos, na própria agenda do movimento, que questionava não só o modelo excludente de transporte, mas também o modelo de cidade, de segurança e de fazer política.

O paradoxo da inclusão pode ser utilizado em uma tentativa de compreender o que levou uma faixa social jovem, com estudo, emprego e renda média a protestar nas ruas. $\mathrm{O}$ avanço no campo democrático acabou por revelar que a inclusão é capaz de 
gerar novas exclusões. Nas últimas décadas, muitas pessoas saíram da linha da miséria, ${ }^{1}$ alcançaram o pleno emprego, ${ }^{2}$ tiveram acesso ao ensino superior ${ }^{3}$ e a bens de consumo de massa. O crescimento acabou por gerar novas aspirações e novas assimetrias. Os novos consumidores passaram a demandar novos direitos, num contexto de novas desigualdades. Um transporte público de melhor qualidade é um desses direitos. O direito à cidade é outro. Somam-se a essas exigências insatisfações com o sistema político em geral, em crise de representação e incapaz de garantir, em sua configuração atual, acesso igualitário aos novos direitos demandados. ${ }^{4}$

Ao que parece, o senso comum já apontava para outras insatisfações antes mesmo dos protestos eclodirem: corrupção, desigualdade, má qualidade dos serviços públicos e gastos exagerados com eventos esportivos, fazendo com que muitos passassem a questionar a prioridade de aplicação de recursos pelos governantes.

Há de se mencionar também a questão urbana para o contexto de gênese das jornadas de junho, constantemente lembrada nos manifestos do Movimento Passe Livre, coletivo de esquerda e idealizador dos protestos. Para o movimento, a cidade é planejada como um modelo de negócio, sejam esses negócios imobiliários, investimentos na indústria de automóveis ou de transferência de serviços à iniciativa privada. Na concepção do Passe Livre, esse planejamento faz com que a população fique apartada da tomada de decisões sobre seu próprio direito à cidade. ${ }^{5}$

Além das "novas exclusões" e dos problemas de conjuntura mencionados, deve-se considerar ainda a influência do contexto internacional para as jornadas de junho. O advento da Primavera Árabe e a organização de movimentos como o Occupy (que se iniciou nos EUA) e os Indignados (Espanha), também disseminados via redes sociais, serviram como forças propulsoras para a proposição de uma agenda de protestos no Brasil. Esses movimentos transformaram pontos geográficos específicos em palcos de protestos tomados por jovens, conectados em redes e indignados contra o "sistema", e tiveram relativo sucesso no desafio de demonstrar ao mundo que o aprofundamento democrático poderia ser alcançado por meio do protagonismo popular.

O número de pessoas vivendo em situação de pobreza extrema no Brasil caiu entre 2001 e 2013, passando de $13.6 \%$ para 4.9\% segundo dados do World Bank. Disponível em: https://data.worldbank.org/indicator/ SI.POV.DDAY?end=2013\&locations=BR\&start=2011\&view=chart. Acesso em: 18 maio 2018.

2 Segundo o IBGE, o desemprego caiu de 12.3\% em 2003 para 5.4\% em 2013. Disponível em: https://www. ibge.gov.br/estatisticas/sociais/trabalho/9180-pesquisamensal-de-emprego.html? $=\& \mathrm{t}=$ series-historicas. Acesso em: 18 maio 2018.

3 Dados do INEP (2014, p. 59) revelam que as matrículas no ensino superior cresceram de 3.887 .022 em 2003 para 5.923.838 em 2012, o que corresponde a um aumento de mais de 52\% no período.

4 A maioria dos manifestantes dizia não se sentir representada por partido (89\%) ou político brasileiro (83\%). IBOPE (2013).

5 Movimentos como Assembleia Popular Horizontal (Belo Horizonte), Bloco de Luta Pelo Transporte (Porto Alegre) e Frente de Luta do Transporte Público (Goiânia), portavam discursos semelhantes. 
Inobstante a melhoria na qualidade de vida e as inclusões em alguns aspectos sociais (ensino superior e pleno emprego), os brasileiros decidiram ir às ruas protestar por direitos ou por melhor aplicação daqueles já garantidos. Os manifestantes de junho seriam aqueles que se sentiram excluídos do acesso a algum direito (ou em situação de ameaça de exclusão), ainda que incluídos em outros. No caso de junho de 2013, a primeira percepção de exclusão foi daqueles que viram o direito ao transporte ser ameaçado.

Para a Teoria dos Sistemas, o futuro é aberto, incerto e imprevisível. Movimentos sociais podem estimular irritação, para que um sistema altere seus futuros padrões de seleção (LUHMANN, 2011b, p. 132). Eles expressam o descontentamento de um grupo, que se identifica em torno do protesto, vinculando este a um tema, para combater uma estrutura que gera (ou pode gerar) exclusão.

$\mathrm{O}$ aumento das tarifas no transporte, ${ }^{6}$ considerado inadequado pela maioria dos usuários, bem como propostas legislativas discriminatórias, como o PDC n. 234/2011, da "cura gay", colocavam direitos em risco. O Movimento Passe Livre, por exemplo, questiona essa estrutura que exclui ou dificulta o acesso ao transporte, sugerindo uma variação com nova proposta que, no seu modo de ver, seria mais inclusiva.

A revogação do aumento em mais de 100 cidades parece ter sido uma das mais relevantes conquistas dos movimentos sociais, desde o fim do regime militar. (VEJA, 2013). Ao tomarem as ruas, manifestantes levaram suas insatisfações e aspirações aos sistemas funcionais, para que esses sistemas processassem suas provocações e oferecessem respostas às reivindicações sociais. Os movimentos de protesto, como os de junho de 2013, podem ser entendidos como alertas críticos à sociedade e aos seus sistemas.

\subsection{O Movimento Passe Livre (MPL)}

O estado da arte da pesquisa sobre as manifestações de junho parece convergir no que diz respeito ao seu início, com os protestos do MPL pelo direito de transporte, diante da decisão de aumento da tarifa em São Paulo. ${ }^{7}$

A demanda de um movimento social é exteriorizada por suas reivindicações. O MPL delimita sua pauta ao propor a revogação do aumento, manifestando sua pretensão de atualizar o sentido das comunicações sistêmicas, para que os preços voltassem ao patamar anterior, alinhando a comunicação interna do sistema às suas expectativas.

\footnotetext{
6 A publicação do Decreto n. 53.935, que reajustou o valor da tarifa de $\mathrm{R} \$ 3,00$ para $\mathrm{R} \$ 3,20$, ensejou mobilização do MPL pelo direito ao transporte, juridicamente garantido pela Constituição Federal $\left(\operatorname{art} .6^{\circ}\right)$.

7 Cf. Castells (2013), Gohn (2013), Nobre (2013), Judensnaider, Lima, Pomar e Ortellado (2013) e Locatelli (2013).
} 
O MPL se define como “autônomo, apartidário, horizontal e independente, que luta por um transporte público de verdade, gratuito para o conjunto da população e fora da iniciativa privada". Por autonomia quer dizer que não depende de organizações ou financiamentos externos para seu desenvolvimento. Declara-se também apartidário, no sentido de não se organizar para eleições, e acreditar que a luta por direitos se dá também fora dos campos políticos institucionais. Já a terceira característica, que o distingue dos movimentos tradicionais, é sua horizontalidade. Horizontalidade designa que "não existe hierarquia neste movimento. Não existe uma direção centralizada onde poucos decidem por muitos. Todos têm igual poder de participação" (TARIFA ZERO, 20--).

Essa terceira característica, que representava até então uma novidade para os movimentos sociais brasileiros, fez com que a mídia e as autoridades governamentais procurassem e não encontrassem lideranças que dialogassem em nome do movimento, acostumadas que estavam em tratar diretamente com interlocutores dos coletivos tradicionais. ${ }^{8}$ A horizontalidade na forma de organização do movimento, bem como sua repulsa aos meios institucionais de disputa pelo poder, acabam por ter consequência na elaboração do meio de atuação do próprio movimento: sua articulação nas redes digitais.

Seus integrantes dominam técnicas associadas à tecnologia e se comunicam, preferencialmente, via redes sociais, com uma linguagem "menos engessada, se comparada aos grupos tradicionais de organizações de esquerda" (JUDENSNAIDER; LIMA; POMAR; ORTELLADO, 2013, p. 15). A comunicação via redes foi fundamental para o movimento, pois permitiu convocações e descrições dos atos em tempo real, atingindo um número antes improvável de receptores em espaço de tempo quase que instantâneo. As jornadas de junho trouxeram, portanto, elementos novos, como a produção em rede, a inteligência colaborativa e a circulação rápida e intensa dos conteúdos digitais para as ruas brasileiras.

O principal objetivo do MPL diz respeito ao direito ao transporte público. O MPL (2005) esclarece que sua pauta se relaciona ainda com outras lutas, como a defesa da liberdade de manifestação e contra criminalização de movimentos sociais. Além disso, o movimento entende que a exclusão do acesso ao direito de transporte estende-se a outras exclusões, como uma espécie de reação em cadeia: "muitas pessoas acabam excluídas da educação porque não podem pagar o ônibus até a escola” (TARIFA ZERO, 20--). ${ }^{9}$

\footnotetext{
8 A dificuldade de interlocução foi percebida por José Eduardo Faria (2013), que questionou a possibilidade de diálogo com um movimento no qual não há definição de lideranças.

9 Esse “encadeamento" das exclusões remete à compreensão de Orlando Villas Bôas Filho (2009, p. 354-355) de que a exclusão pode ser bastante integrada no âmbito dos sistemas sociais.
} 
A atuação do MPL nas manifestações se iniciou com a divulgação do aumento da tarifa, de $\mathrm{R} \$ 3,00$ para $\mathrm{R} \$ 3,20$, conforme Decreto n. 53.935, publicado em 25 de maio de 2013, no Diário Oficial de São Paulo, e se estendeu por todo o mês de junho.

Pelos dados da pesquisa Datafolha (13 jun. 2013), a percepção que se tem é que o aumento do preço da tarifa revelou certo contraste entre a qualidade do serviço e o valor por ele cobrado, constatação esta que pode auxiliar na explicação da motivação dos protestos. A pesquisa demonstrou que $73 \%$ dos presentes nos protestos utilizam o ônibus como meio de transporte. Também responderam que utilizam metrô (39\%), carro (27\%), trem $(18 \%)$ e lotação (15\%). O número de usuários que utilizam o transporte público para se deslocar é, portanto, significativo, comparado ao número se desloca de outra forma.

Um segundo fator condicionante parece ser a qualidade do serviço prestado: apenas $15 \%$ dos paulistanos o consideram bom ou ótimo. A mesma pesquisa também revelou outro fator condicionante: $75 \%$ dos entrevistados consideram as tarifas de transporte "caras" ou "muito caras", enquanto que, para $23 \%$, as tarifas são adequadas, e somente $2 \%$ as classificam como baratas. Os dados sugerem, portanto, que o alto número de usuários de transporte público, em um ambiente em que as tarifas são consideradas caras e de má qualidade, motivaram as pessoas na adesão à pauta do MPL.

Por outro lado, ainda que o MPL se identifique pela luta contra um modelo excludente de transporte público, o perfil dos manifestantes revela que nem todos se encontravam em situações específicas de exclusão, mas que esses participantes, de algum modo, podem ter se sensibilizado com a pauta e decidiram aderir aos protestos.

É importante destacar que a influência do MPL se deu de forma mais intensa durante a primeira fase das manifestações, que compreende no protesto realizado no dia 3 ao ato realizado no dia 13 de junho. ${ }^{10}$ No dia 21 , o movimento chegou a divulgar sua retirada das ruas, sob a alegação de que as manifestações passaram a assumir características conservadoras, mas decidiu retornar no dia seguinte.

\subsection{O coletivo Anonymous}

Apesar de seu protagonismo inicial, o MPL não é o único movimento importante para a análise do cenário das manifestações de junho. O coletivo Anonymous também teve efetiva participação nos protestos, principalmente na segunda fase das manifestações.

10 Em uma hipotética linha do tempo, as manifestações podem ser divididas em duas fases. A primeira vai do início de junho até o ato do dia 13. Nesse período, as manifestações eram menores e se delimitaram à pauta do transporte. A segunda fase, marcada por atos com maior expressividade e reivindicações difusas, compreende desde o protesto do dia 17 até o arquivamento do PDC da "cura gay", em 2 de julho. 
O Anonymous, existente desde 2003, é um coletivo digital de ativistas atuante em escala global, que se organiza como comunidade descentralizada, se autodeclara progressista e diz acreditar em princípios como "esperança, dignidade e justiça". O coletivo repudia qualquer forma de identificação de lideranças. ${ }^{11}$

As ideias que representam seu pensamento são normalmente relacionadas a direitos sociais e liberdade de expressão. O movimento se popularizou a partir de 2008, e ganhou notoriedade na defesa do WikiLeaks, site de denúncias que publica informações sensíveis vazadas de fontes governamentais ou de empresas de grande porte, criado pelo ativista Julian Assange. Desde então, o Anonymous oferece suporte a causas por meio de sua atuação via internet.

Além das especificidades já citadas, outra característica notável é que todos os membros ocultam suas identidades, ou seja, agem no anonimato (DANET; BARDEAU, 2011). ${ }^{12}$ O movimento justifica essa atuação como forma de autoproteção.

Quando saem às ruas, seus integrantes cobrem seus rostos com uma máscara que evoca o personagem $V$ de Vingança (inspirado em Guy Fawkes, que, em 5 de novembro de 1605, tentou explodir o Parlamento inglês). O uso da máscara, ícone da cultura pop, auxilia na compreensão do interesse e da adesão do público jovem ao movimento.

Durante as jornadas de junho, a atuação do Anonymous se destacou a partir dos atos realizados no dia 13 (marcado pela violência policial). O grupo passou a realizar ataques a sites institucionais, no sentido de oferecer suporte à demanda do MPL e, além disso, a divulgar nas redes imagens e vídeos que demonstravam os excessos da polícia sobre os manifestantes. Esses vídeos tornaram-se virais.

A relevância do Anonymous nas manifestações deve ser reconhecida, considerando que, na segunda fase dos protestos, 12 dos 20 perfis com maior alcance em compartilhamento de informações sobre os protestos pertenciam ao grupo, segundo pesquisa divulgada pela Folha de S. Paulo. O coordenador da pesquisa qualificou o desempenho do Anonymous como decisivo para disseminação das informações e na articulação da solidariedade às manifestações. (VALENTE; MAGALHÃES, 2013). O movimento teve, portanto, importância fundamental para a amplitude dos protestos, especialmente por seu engajamento, via redes sociais, com a finalidade de convocar a população para os atos de rua.

11 Anonymous Brasil. Disponível em: http://www.anonymousbrasil.com/sobre-anonymous/. Acesso em: 18 maio 2018.

12 Segundo Whipple (2008) e Fontanella (2010), o conceito de anonimato do grupo foi inspirado na atuação de pessoas em imageboards, que se baseia na postagem de imagens e texto, geralmente de forma anônima. 
Por outro lado, o alastramento das manifestações, verificado a partir do dia 17, trouxe consigo um número considerável de novos manifestantes, e, com eles, novas reivindicações, que inicialmente não faziam parte das demandas do MPL.

1.3. Perfil dos manifestantes e reivindicações difusas: solidariedade e críticas generalizadas

Sustentou-se, até aqui, que o MPL foi o principal responsável pelos protestos, e que o Anonymous atuou como suporte, com ativa participação na segunda metade do mês. Dados sugerem que ambos os movimentos têm forte apelo e ingerência entre o público jovem, escolarizado, empregado e conectado em rede, conforme interpretação extraída de pesquisas realizadas pelo Datafolha (DATAFOLHA, 2013a; DATAFOLHA, 2013b) e pelo Ibope (2013).

O Ibope revela também a capacidade de mobilização, via internet, do movimento: $75 \%$ dos manifestantes convocaram outras pessoas para participar das manifestações via Facebook, o que parece comprovar o caráter em rede dos protestos.

Segundo o Datafolha (18 jun. 2013), a questão da tarifa aparece como principal motivo mencionado pelos manifestantes ao justificar o porquê dos protestos. Com a evolução dos atos, outras reivindicações passam a fazer parte da agenda das manifestações, a ponto de o MPL afirmar que sua "luta foi tomada de assalto pela difusão de pauta” (JUDENSNAIDER; LIMA; POMAR; ORTELLADO, 2013, p. 235).

Além dos $67 \%$ dos entrevistados que apontam como motivo principal o aumento da passagem, outras razões mencionadas de forma significativa pelos manifestantes são o combate à corrupção (38\%), a insatisfação política (35\%), a violência (18\%), e problemas institucionais específicos, como à saúde (7\%), educação (5\%) e outros $(10 \%)$. A mesma generalidade nas reivindicações pode ser verificada na pesquisa nacional realizada pelo Ibope (20 jun. 2013). Na indagação sobre os motivos das manifestações, $54 \%$ dos entrevistados justificam sua participação em razão da causa do transporte, enquanto admitiam outras insatisfações em complemento à demanda principal.

As pesquisas sugerem crítica generalizada de sistemas (política, educação, economia), num misto de percepção de ameaça de exclusão de direitos com participação por solidariedade. Os pequenos atos relacionados ao transporte se transformaram em manifestações com interesses que reivindicavam uma grande variedade de temas, como reforma política, fim da repressão policial, fim da inflação, qualidade nos serviços públicos, não aprovação de projetos como a "cura gay" e a PEC n. 37.

Dentre tantas reivindicações, três situações foram selecionadas como amostragem, a fim de que seja possível demonstrar, de forma experimental, como os movimentos sociais provocam irritação nos sistemas funcionais ao demandar por 
direitos. As reivindicações e seu processamento são tratados como eventos sociojurídicos, interdependentes entre si. A luta pelo direito de transporte (evento 1) enseja repressão policial ao direito de manifestação (evento 2). Na sequência, após a repercussão dos atos violentos pela mídia (variável), reivindicações como o arquivamento dos projetos de alteração constitucional passam a fazer parte da pauta dos manifestantes (evento 3).

2. Indiferença, conservação e mudança: verificação das hipóteses

Este tópico tem por finalidade descrever as provocações das manifestações e as reações sistêmicas a elas. A hipótese é experimentada a partir de um estudo acerca da origem e dos resultados das manifestações, no contexto juspolítico brasileiro.

Metodologicamente, destaca-se que os dados utilizados para a demonstração hipotética são oriundos do centro do sistema jurídico (no que diz respeito às decisões judiciais), bem como de sua periferia, na zona de contato com a política (nos dados relacionados à polícia e às autoridades políticas, e aos que tratam de projetos de leis), e ainda do sistema midiático (notícias). A investigação sobre o tratamento da mídia dado aos protestos é relevante porque significou uma reinterpretação do direito à manifestação, no decorrer dos protestos. Essa reinterpretação é tratada como variável interveniente no processo de tratamento das hipóteses da conservação e da mudança.

\subsection{As primeiras provocações: hipótese da indiferença}

Antes de um sistema reagir às provocações e processá-las sob seus mecanismos, é preciso considerar que, em um cenário de contingência, a não reação também é uma possibilidade. Para Luhmann (1989), é provável que um movimento social não consiga provocar irritações em determinado sistema. Muitas vezes, as expectativas e o sentido por meio do qual o sistema opera é muito diverso daquela atualização pretendida pelo movimento. Se o movimento for incapaz de produzir irritações tangíveis no ambiente do sistema, este poderá manter-se indiferente às suas pretensões.

Os sistemas provocados poderiam não processar as demandas reivindicadas, caso os protestos seguissem os parâmetros daqueles realizados em anos anteriores, quando as pretensões foram ignoradas. Em 2010, por exemplo, o MPL não conseguiu se mobilizar a ponto de reverter o aumento da tarifa de transporte na capital paulista, que passou de $\mathrm{R} \$ 2,30$ para $\mathrm{R} \$ 2,70$. O mesmo ocorreu em 2011, quando houve reajuste para $\mathrm{R} \$ 3,00$.

As primeiras movimentações contra o aumento da tarifa, em São Paulo, ocorreram no dia 3, foram regionais e descentralizadas, em localidades como Parque Dom Pedro, Pirituba, Vila Leopoldina e Estrada do M'Boi Mirim. (LEANDRO, 2013). Esses primeiros atos não despertaram reações sistêmicas, e continuaram de forma esporádica até o dia 6. 
No dia 6, o MPL decidiu realizar outro protesto, em frente à Prefeitura Municipal. Esse protesto ficou conhecido como primeiro grande ato. A polícia foi acionada para conter os manifestantes, e autoridades desqualificaram as reivindicações. O governador Geraldo Alckmin, chegou a afirmar, via Twitter, que o vandalismo dos manifestantes "prejudica a população". No dia seguinte, o prefeito de São Paulo, Fernando Haddad, convocou integrantes do MPL para reunião a fim de discutir a questão do transporte.

Considerando a abertura de canais de diálogo e o acionamento da polícia como primeiras reações sistêmicas, a hipótese da indiferença aparenta não se sustentar. Diante disso, é possível afirmar que as manifestações de junho provocaram os sistemas com uma proposta de um novo sentido comunicacional sobre direitos. Os sistemas precisam então decidir se processam ou não as demandas dos manifestantes, por meio de seus mecanismos de operacionalização. Descartada a hipótese da indiferença, as expectativas do movimento podem ser respondidas nas formas de conservação ou de mudança.

\subsection{Repressão e criminalização do movimento: hipótese da conservação}

A hipótese da conservação diz respeito à possibilidade de que sistemas se transformem em instrumentos de repressão para controlar ações dos manifestantes. $\mathrm{O}$ direito, por exemplo, pode ser invocado para rechaçar exigências e contrapor pressões sociais (LUHMANN, 2004, p. 153). Nessa concepção, a violência policial é uma das formas de acoplamento entre direito e política. A mobilização da polícia pode ser entendida como uma resposta conservadora às demandas de um movimento social.

Os dados extraídos de notícias sobre ações policiais, prisões e detenções, decisões judiciais, pronunciamentos de autoridades e projetos de lei parecem indicar que a reação inicial dos sistemas provocados foi no sentido da conservação.

Em São Paulo, a tentativa de reprimir o movimento começou a tomar forma a partir do dia 6 e se estendeu até o dia 13 de junho. $O$ ato realizado no dia 6 contou com pelo menos 15 detidos. As detenções se deram sob o fundamento de crime de dano ao patrimônio público, formação de quadrilha ou para averiguação. A repressão ao movimento se intensificou a partir do dia 7, no denominado segundo grande ato, que reuniu 5 mil pessoas. A polícia utilizou bombas de efeito moral e de gás lacrimogêneo para impedir que os manifestantes ocupassem faixas da Marginal Pinheiros. ${ }^{13} \mathrm{O}$ prefeito de São Paulo continuou a negar a viabilidade das demandas do movimento. (RODRIGUES, 2013).

13 No dia 8, editorial do Estado de S. Paulo reforçou o discurso antivandalismo e clamou por rigor na ação policial. Os manifestantes foram qualificados como "vândalos". (PURO, 2013). 
O governador de São Paulo também depreciou o movimento. Ele chegou a classificar os manifestantes como "vândalos e baderneiros", ao comentar o assunto em 11 de junho. Além disso, elogiou a polícia, afirmando que ela "agiu com profissionalismo ao reprimir atos inaceitáveis de vandalismo e baderna". (NETTO, 2013). O protesto do dia 11 (terceiro grande ato) teve como saldo dezenas de pessoas feridas e 20 pessoas detidas. (MORA; VIANA, 2013).

Além da repressão policial, autoridades jurídicas também desqualificaram os protestos, de forma conservadora: parte-se do pressuposto de que movimentos sociais são formados por vândalos, que devem ser contidos a qualquer custo. ${ }^{14}$

Adicionalmente, estudos do Instituto Brasileiro de Ciências Criminais reafirmam a hipótese da conservação, pois indicam que as manifestações em São Paulo "foram caracterizadas pela truculência e violência da polícia ao, supostamente, tentar conter os manifestantes", e que ficou "evidente a falta de habilidade do Estado para lidar com o exercício legítimo dos direitos de reunião e livre manifestação, apoiando-se na repressão policial como forma de conter - se é que algo precisava ser contido - os manifestantes". (TAFFARELLO, 2013).

Em sequência, o quarto grande ato, realizado no dia 13, ficou marcado como o mais violento de todo aquele mês. A polícia indicou que não toleraria atos de depredação, reforçando seu contingente com a tropa de choque. (NETTO, 2013). De acordo com o MPL, cerca de 20 mil pessoas participavam do protesto (JUDENSNAIDER; LIMA; POMAR; ORTELLADO, 2013, p. 94), quando a polícia resolveu dispersar o movimento, para impedi-lo de chegar à Avenida Paulista. A tentativa de dispersão fracassou e a região tornou-se palco de cenas lamentáveis: manifestantes perseguidos por policiais, que os alvejavam com balas de borracha e bombas de concussão. Essa repressão foi registrada por vídeos amadores, que foram imediatamente compartilhados via redes sociais.

No que tange ao centro do sistema jurídico, dentro do recorte delimitado, apurou-se que os tribunais também reagiram de forma predominantemente conservadora em relação às manifestações. As decisões, na maioria dos casos, contêm pouca argumentação técnico-jurídica propriamente dita. Os julgadores recorreram a argumentos retóricos para legitimar o uso do aparato policial para controle e contenção dos manifestantes. ${ }^{15}$

A título exemplificativo, decidiu-se, no processo 002401095.2013.8.26.0053 (TJ/SP), que as prisões para “averiguação" realizadas durante os protestos foram legais, inclusive de manifestantes que portavam vinagre (que reduz os

14 P. ex.: a postagem publicada pelo promotor Rogério Leão Zagallo. Sua declaração repercutiu negativamente nas redes e no meio acadêmico, e acabou por ensejar sua demissão do cargo de professor da Universidade Mackenzie, após pressão do Centro Acadêmico da Faculdade de Direito. (SP, 2013).

15 Foram analisadas 10 decisões proferidas pelos tribunais dos Estados de São Paulo e do Rio de Janeiro, que trataram das prisões de manifestantes. 
efeitos das bombas de gás). O magistrado argumentou que a atuação policial se baseou no princípio da garantia da ordem pública, e que o judiciário não deveria adotar medidas com o escopo de dificultar o policiamento. Além disso, o julgador considerou que a condução de manifestantes à delegacia não foi ilegal. $\mathrm{O}$ decisor, entretanto, não informou as razões pelas quais considerou que os manifestantes fossem suspeitos.

Em outro caso, o Ministério Público do Rio de Janeiro denunciou a ativista conhecida como "Sininho", junto com outras 22 pessoas, pelos crimes de formação de quadrilha e de corrupção de menores, por suspeita de promoverem violência durante as manifestações (0229018-26.2013.8.19.0001). A defesa revelou que houve investigação partidária, o que indicaria persecução criminal a grupos de "esquerda". Para a defesa, a acusação se esforçou para enquadrar a participação dos envolvidos na tipificação do art. 288 (associação criminosa), pois não há descrição dos elementos para tipificação do delito de quadrilha. A participação dos envolvidos em outro ato (evento que rememorou os atos de violência contra professores) bastou para que o tribunal decidisse por decretar a prisão dos manifestantes, com base no descumprimento das medidas preventivas.

A análise das decisões indica para uma incompreensão das autoridades jurídicas acerca do direito de manifestação, talvez por tratar-se de uma demanda pouco difundida no judiciário brasileiro. Além disso, a ausência de regulação específica sobre o tema parece dificultar a aplicação da lei pelos julgadores, que, diante desse quadro, despendem de esforços interpretativos para legitimar a atuação policial e enquadrar as ações dos manifestantes em tipos penais elaborados para contextos de repressão democrática.

As manifestações de junho trouxeram à tona a ausência de regulamentação e de estabelecimento de limites acerca do próprio direito de manifestação. Até o momento, não parece haver legislação adequada no Brasil que regulamente o direito à manifestação. O sistema jurídico, em sua atual configuração, aparenta repelir as demandas manifestadas dos movimentos sociais. Nesse cenário, manifestantes foram enquadrados na Lei de Segurança Nacional e na Lei de Organização Criminosa. Isso trouxe indignação dos defensores dos movimentos sociais, sob a alegação de que não é razoável enquadrar militantes como criminosos, com base em leis que contém resquícios ditatoriais.

Depois das manifestações de junho, diversos projetos de lei propondo a regulamentação de manifestações foram apresentados no Congresso. ${ }^{16}$ Os assuntos tratados são diversos e envolvem os mesmos temas: regulação de protestos, proibição

16 P. ex.: PL n. 6.500/2013 (BRASIL, 2013b), que dispõe sobre a aplicação do princípio da não violência e garantia dos direitos humanos em manifestações e eventos públicos; PL n. 6.198/2013 (BRASIL, 2013a), que pretende proibir o uso de máscaras e outros materiais usados para esconder o rosto durante manifestações populares. 
do uso de máscaras, proibição do uso de armas de baixa letalidade e alteração/criação de novos crimes. As jornadas de junho, portanto, tocaram num ponto nevrálgico e revelaram os limites do processo de consolidação democrática do Brasil, com resquícios autoritários e dificuldade de compreensão de demandas populares. A repressão não partiu somente da polícia, mas também do Ministério Público e do Poder Judiciário, muitas vezes sincronizados no intuito de criminalizar protestos. A repressão ao movimento parece relacionar lutas por direitos à baderna e ao vandalismo. Os dados analisados ratificam a hipótese da reação sistêmica conservadora às manifestações.

\subsection{As vitórias do movimento: hipótese da mudança}

A partir do dia 17, a participação nas manifestações atingiu novo patamar. Nessa segunda fase, os atos foram, majoritariamente, pacíficos. O protesto do dia 17 (quinto grande ato) evidenciou a difusão de pauta. A centralidade da questão do transporte deu lugar a uma variada gama de insatisfações. Na concepção do MPL, a mídia foi responsável pela dispersão das pautas.

A atuação da mídia pode ser compreendida como variável interveniente no processo descritivo das manifestações e de suas provocações: em razão da construção de uma nova narrativa sobre o ocorrido, as manifestações se intensificaram a ponto de provocar, de forma mais contundente, o direito e a política. Não fosse essa variável, o movimento possivelmente não teria atingido proporções significativas.

Veículos alternativos esforçaram-se para produzir uma narrativa distinta. Midiativistas foram capazes de contraditar a narrativa até então dominante, contrapondo seu discurso com imagens transmitidas em tempo real. O próprio Luhmann (2011a, p. 76), ao refletir sobre os meios de comunicação, sustenta que não há nada tão impactante no contexto comunicacional como a contraposição da imagem contra a imagem.

A violência policial passou a ser transmitida online pelos manifestantes, e ensejou maior adesão aos atos. Devido ao intenso compartilhamento em rede, as manifestações passaram a ganhar maior visibilidade nacional e internacional. O discurso inicial de criminalização do movimento deu lugar a um discurso de legitimação.

A mudança no discurso teve um preço: a mídia tentou ressignificar a pauta dos protestos e teve relativo sucesso: a demanda por direitos relacionados ao transporte foi colocada em segundo plano, e teve seu foco deslocado para o combate à corrupção, críticas ao governo e aos gastos com a Copa do Mundo.

Sabendo que o ato do dia 17 estaria em evidência, o governo de São Paulo, até então muito criticado, determinou atenuação da atuação policial e descartou o uso da tropa de choque. O secretário de segurança chegou a afirmar que o direito de manifestação poderia ser exercido livremente e que excessos policiais seriam apurados. (GRELLA, 
2013). O comando da polícia também proibiu que agentes atuassem sem a tarjeta de identificação (como ocorreu nos protestos anteriores). Esses "gestos" de aproximação do governo podem ser compreendidos como indícios de superação da hipótese da conservação.

Movimentos das mais diversas orientações ideológicas divulgaram apoio e participação no ato do dia $17 .{ }^{17}$ Até mesmo a então presidenta Dilma recomendou a baixa na tarifa do transporte (CASTELLS, 2013, p. 185).

O protesto do dia 17 superou as expectativas da imprensa e do próprio MPL (JUDENSNAIDER; LIMA; POMAR; ORTELLADO, 2013, p. 162). São Paulo reuniu 65 mil pessoas. No Rio de Janeiro, 100 mil participaram da manifestação. No total, as manifestações do dia 17 ocorreram, de forma expressiva, em 13 capitais. A polícia apenas acompanhou o ato, sem intervenção. O MPL ganhou visibilidade com a dimensão do ato do dia 17. Em entrevista ao Roda Viva, o movimento garantiu que não deixaria as ruas enquanto a tarifa não baixasse, e salientou a importância do direito ao transporte para o acesso a outros direitos.

O saldo dos protestos do dia 17 foi de intenso apoio às manifestações, tanto dos veículos de comunicação quanto da população em geral, conforme dados extraídos de pesquisas realizadas pelo Datafolha e pelo Ibope, a seguir representadas:

Tabela 1 - Aprovação às manifestações

\begin{tabular}{|l|l|l|l|l|}
\hline \multicolumn{1}{|c|}{ Abrangência } & Favorável & \multicolumn{1}{c|}{ Contra } & \multicolumn{1}{c|}{ Indiferente } & Não sabe \\
\hline São Paulo & $\mathbf{7 7 \%}$ & $\mathbf{1 8 \%}$ & $\mathbf{5 \%}$ & $<\mathbf{1 \%}$ \\
\hline Brasil & $\mathbf{7 5 \%}$ & $\mathbf{2 2 \%}$ & - & $\mathbf{3 \%}$ \\
\hline
\end{tabular}

Fonte: Datafolha, 18 jun. 2013; Ibope, 20 jun. 2013.

A pressão sobre as autoridades por uma resposta diferente da repressão se evidenciou após o dia 17. No dia seguinte, aconteceu em São Paulo o sexto grande ato convocado pelo MPL. As pessoas foram para a rua, com todas as suas diferenças políticas e ideológicas, divididas em grupos pouco homogêneos.

O Anonymous passou a ser visto como grande articulador dos protestos nas redes, colocando em xeque o protagonismo do MPL. A pressão dos movimentos começou a dar resultado ainda no dia 18: o aumento na tarifa foi revogado em Cuiabá, João Pessoa, Pelotas, Montes Claros, Foz do Iguaçu, Porto Alegre e Recife.

17 O evento criado no Facebook para o Quinto Ato contava com 200 mil pessoas inscritas, número muito maior que a capacidade real de mobilização do MPL. 
A vitória na demanda básica do movimento, nas duas maiores cidades do Brasil, ocorreu no dia seguinte: diante da massificação dos protestos, autoridades se viram pressionadas e, no dia 19, anunciaram a redução das tarifas do transporte. Em São Paulo, o governador mencionou "compromisso com a cidade" e passou a considerar os temas levantados como legítimos, enquanto o prefeito falou de "gesto de aproximação e de abertura" e relacionou a redução dos preços aos movimentos de rua e ao fortalecimento do "espírito democrático". A decisão foi normatizada por meio do Decreto n. 54.016, de 19 de junho de 2013, que reduziu o valor da tarifa para R\$ 3,00. Ao mesmo tempo, no Rio de Janeiro, o prefeito Eduardo Paes anunciou a suspensão do aumento da passagem.

Não fosse a pressão ocasionada pelas manifestações, a revogação do aumento das tarifas de transporte não teria ocorrido, considerando a resistência inicial e a posterior mudança de atitude dos governantes após a intensificação dos protestos.

Na perspectiva de Luhmann (2004, p. 372), quando há pressão suficiente, a legislação pode se pôr em marcha e chegar a termo, com relativa rapidez. A promulgação ou a revogação de uma lei (ou seja, a resposta do direito, na direção desejada pela política) é um símbolo de êxito dessa pressão. $\mathrm{O}$ atendimento às demandas dos manifestantes pode ser compreendido a partir dessa perspectiva de sucesso resultante da mobilização social.

Importante destacar que o sucesso na questão do transporte não foi suficiente para tirar os manifestantes das ruas, que passaram a intensificar a luta por outras demandas, de forma ainda mais difusa. Isso revela a relação entre o aumento no transporte e o início das manifestações, e também que outras reivindicações se intensificaram, em razão do aumento do alcance dos protestos e do atendimento à demanda inicial, como o arquivamento dos projetos de alteração constitucional PEC n. 37/2011 e PDC n. 234/2011.

A PEC n. 37 pretendia alterar a competência investigativa e retirar a prerrogativa do Ministério Público (MP). Pressionados, os deputados optaram pelo seu arquivamento.

A oposição à PEC n. 37 já era um tema em discussão antes mesmo do início das manifestações. ${ }^{18}$ Com o aumento do número de manifestantes, essa discussão passou a ocorrer em nível nacional, com ampla cobertura midiática e engajamento popular.

Durante as manifestações, em enquete realizada pelo UOL, em 13 de junho, mais de $95 \%$ dos participantes afirmaram ser contrários à proposta. $\mathrm{O}$ combate à $\mathrm{PEC} \mathrm{n}$. 37 passou então a ser um dos temas mais mencionados durante os protestos. ${ }^{19}$ Além disso,

18 Para Lemos (2015, p. 12), “as associações do MP já estavam atuando contra a aprovação da PEC pelo menos desde abril de 2012, quando a comissão especial para examinar a proposta foi instalada”.

19 A PEC n. 37 figurou entre os temas mais mencionados nas redes sociais, tendo alcançado o primeiro lugar no dia 25 , com $12.8 \%$ das menções, de acordo com monitoramento da plataforma Causa Brasil. 
em pesquisa realizada pelo Datafolha durante os protestos de 20 de junho, em São Paulo, $16 \%$ dos entrevistados mencionaram sua oposição à aprovação da PEC n. 37.

A PEC n. 37 sofreu expressiva derrota, quando votada no dia 25 de junho. Um deputado chegou a argumentar que: "se a votação fosse há 15 dias, com certeza seria aprovada. A vitória é uma vitória do povo que foi às ruas. Foi por causa da presença da população nas ruas, exigindo a derrota da PEC n. 37, que nós a enterramos. Não fosse isso, ela fatalmente seria aprovada". ${ }^{20}$

$\mathrm{O}$ MP conseguiu, portanto, inserir uma demanda específica em meio às reivindicações presentes nos protestos de junho, obtendo amplo apoio dos manifestantes, que pressionaram os sistemas para rejeitar a proposta que possivelmente seria vitoriosa, não fossem as mobilizações sociais. ${ }^{21}$

$\mathrm{O}$ apoio dos manifestantes ao MP sugere até mesmo um fortalecimento da própria instituição, que passou a contar com o suporte da opinião pública no combate à impunidade, especialmente em casos de corrupção.

Ainda no esteio das manifestações, outra demanda foi a derrubada da proposta 234/2011, conhecida como "cura gay", que tinha por finalidade "sustar a aplicação do parágrafo único do art. $3^{\circ}$ e o art. $4^{\circ}$, da Resolução do Conselho Federal de Psicologia n. 1/99, que estabelece normas de atuação para os psicólogos em relação à orientação sexual". A controversa proposta foi aprovada pela Comissão de Direitos Humanos e Minorias (CDHM), presidida pelo Pastor Marcos Feliciano, em 18 de junho de 2013.

O projeto, dotado de características discriminatórias por equiparar a homossexualidade a uma doença, afrontava o princípio da dignidade humana (art. $1^{\circ}$, inciso III da Constituição Federal). Atos organizados em cidades como São Paulo (21 de junho), Porto Alegre (26 de junho), e Rio de Janeiro (28 de junho) pressionaram no sentido de propor a rejeição ao projeto.

A Ordem dos Advogados do Brasil também manifestou seu repúdio à proposta e afirmou ser esta "mais um dos absurdos cometidos pela chamada Comissão de Direitos Humanos da Câmara dos Deputados" e que "é lamentável uma proposição como essa justamente no momento em que o país assiste a uma mobilização social capaz de enfrentar práticas fundamentalistas e dar efetividade à defesa e garantia dos direitos humanos".

Diante da rejeição popular, o presidente da Câmara dos Deputados decidiu colocar o texto para apreciação em plenário, com o objetivo de “enterrar” a proposta

\footnotetext{
20 Alessandro Molon (PT/RJ) em entrevista à Agência Brasil. (CRUZ; COURA, 2013).

${ }^{21} \mathrm{O}$ Estado de S. Paulo tratou da rejeição da proposta como resultado direto da pressão das ruas. (REJEIÇÃO, 2013).
} 
publicamente, mostrando à sociedade que a maioria da Casa se posicionava de forma contrária à medida. Prevendo derrota e desgaste, a bancada evangélica decidiu recuar e optou por requerer a retirada da proposição. A queda veio efetivamente a ocorrer no dia 2 de julho, a pedido do autor, que, sem apoio do seu próprio partido, acabou por ceder às demandas das ruas. O projeto, então, foi arquivado.

\section{Conclusão}

As manifestações de junho de 2013 conquistaram mudanças específicas relacionadas a direitos, ainda que os sistemas jurídico e político, no recorte analisado, pareçam atuar predominantemente de forma conservadora diante dos movimentos sociais.

$\mathrm{O}$ estudo indica que os protestos levaram às ruas uma camada da população pouco engajada politicamente até então, que propôs demandas pouco específicas, ao lado de reivindicações pontuais, como a da redução das tarifas. Os sistemas não se portaram de forma indiferente às provocações, pois as processaram e reagiram, diferente do que acontecia em protestos anteriores do MPL (hipótese da indiferença).

Com a intervenção da mídia (variável), os protestos se intensificaram, resultando em maior divulgação dos abusos cometidos pela polícia (hipótese da conservação), que ocasionou maior adesão e aglutinação de novas reivindicações.

Os sistemas, não indiferentes às manifestações e com tendência conservadora, passaram a considerar as demandas propostas diante da amplitude dos protestos, o que resultou na revogação do reajuste nas tarifas do transporte público, bem como na derrubada dos projetos de alteração constitucional (hipótese da mudança).

Tais concessões do direito e da política diante dos movimentos sociais não devem ser interpretadas como atentados à autonomia desses sistemas, mas como estímulos que podem ocasionar na sua própria evolução: os conflitos provocados pelos movimentos sociais podem estimular a evolução do direito. Nas palavras de Luhmann (2004, p. 476), "sem conflitos o direito não surgiria, ou então não se renovaria e seria esquecido".

Junho de 2013 acabou por estimular o desenvolvimento do próprio sistema jurídico: novos marcos decisórios foram criados onde existiam lacunas e novos projetos regulatórios foram postos em discussão. É possível que até mesmo o Ministério Público tenha se fortalecido, ao conseguir alinhar suas expectativas à opinião pública e aos meios de comunicação de massa, num discurso de combate à corrupção.

As jornadas de junho também inovaram no âmbito político. A organização em redes parece ter tido um impacto nas formas de atuação da política: há, desde então, intensa preocupação com o monitoramento de redes sociais, devido ao alcance e a rapidez proporcionada pelo ambiente virtual. O Palácio do Planalto admitiu que, após ser pego de surpresa pelos protestos de junho, passou a fazer uso de agências de processamento de 
dados, a fim de identificar influenciadores nas redes e as principais demandas políticas. As informações são enviadas a órgãos públicos, inclusive agentes de segurança.

A atuação e organização em rede, onipresente nos protestos, pode ter sido a principal contribuição das manifestações de junho de 2013 para as formas de atuação dos movimentos sociais contemporâneos no Brasil. A possibilidade de reestruturação do tempo físico (instantaneidade da informação) e espacial (compartilhamento em grande escala quantitativa), a partir do uso de ferramentas tecnológicas no ambiente virtual foi fundamental para que o movimento alcançasse sucesso em suas demandas por direitos.

As jornadas de junho de 2013 reafirmaram o espaço público como local de reivindicações e de lutas por direitos, aperfeiçoado pela atuação em rede dos manifestantes. É crucial entender junho como um momento de abertura democrática da participação popular no Brasil e de confirmação do sentimento de esperança de mudança, através da mobilização social. Num cenário de contingência e complexidade, a mudança, a partir da demanda por direitos, nunca é uma certeza, mas uma possibilidade.

São Paulo, maio de 2018.

\section{Referências}

ANONYMOUSBRASIL. 2013. Disponível em: http://www.anonymousbrasil.com/sobreanonymous. Acesso em: 18 maio 2018.

BRASIL. Câmara dos Deputados. Projeto de Lei n. 6.198/2013. Brasília, DF, 2013a. Disponível em: https:/www.camara.leg.br/proposicoesWeb/fichadetramitacao?idProposicao=589500. Acesso em: 18 maio 2018.

BRASIL. Câmara dos Deputados. Projeto de Lei n. 6.500/2013. Brasília, DF, 2013b. Disponível em: https:/www.camara.leg.br/proposicoesWeb/fichadetramitacao?idProposicao=595185. Acesso em: 18 maio 2018.

CAMPILONGO, Celso Fernandes. Interpretação do direito e movimentos sociais. Rio de Janeiro: Elsevier, 2012.

CASTELLS, Manuel. Redes de indignação e esperança: movimentos sociais na era da internet. Tradução de Carlos Alberto Medeiros. Rio de Janeiro: Zahar, 2013.

CRUZ, Luciene; COURA, Beto (ed.). Manifestações foram decisivas para derrubada da PEC 37, diz Deputado. Portal EBC, Brasília, 26 jun. 2013. Disponível em: http://www.ebc.com.br/noticias/ politica/2013/06/deputado-diz-que-manifestacoes-foram-decisivas-para-derrubada-da-pec-37. Acesso em: 18 maio 2018.

DANET, Nicolas; BARDEAU, Frédéric. Anonymous, peuvent-ils changer le monde? Paris: FYP, 2011. 
DATAFOLHA. Contagem da manifestação no Largo da Batata. São Paulo, 17 jun. 2013. Disponível em: http://media.folha.uol.com.br/datafolha/2013/06/19/contagaem-manifestacao-lgo-da-batata. pdf. Acesso em: 18 maio 2018.

DATAFOLHA. Opinião sobre as manifestações. São Paulo, 21 jun. 2013. Disponível em: http:// media.folha.uol.com.br/datafolha/2013/06/24/opiniao-sobre-as-manifestacoes.pdf. Acesso em: 18 maio 2018.

FARIA, José Eduardo. De maio de 1968 a junho de 2013. O Estado de S.Paulo, São Paulo, 10 jul. 2013. Disponível em: https://opiniao.estadao.com.br/noticias/geral,de-maio-de-1968-a-junho-de2013-imp-,1051885.

FONTANELLA, Fernando. Nós somos Anonymous: anonimato, trolls e a subcultura dos imageboards. In: CONGRESSO BRASILEIRO DE CIÊNCIAS DA COMUNICAÇÃO, 33., 2010, Caxias do Sul. Anais [...] São Paulo: Sociedade Brasileira de Estudos Interdisciplinares da Comunicação, 2010. Disponível em: http://www.intercom.org.br/papers/nacionais/2010/resumos/ R5-1964-1.pdf.

GOHN, Maria da Glória. Manifestações de junho de 2013 no Brasil e praças dos indignados no mundo. Petrópolis: Vozes, 2013.

GRELLA, Fernando. Governo de SP descarta Tropa de Choque em novo protesto. O Estado de $S$. Paulo, São Paulo, 16 jun. 2013. Disponível em: http://www.estadao.com.br/noticias/geral,governode-sp-descarta-tropa-de-choque-em-novo-protesto,1043200. Acesso em: 18 maio 2018.

IBGE. Pesquisa mensal de emprego - PME. Rio de Janeiro, 2013. Disponível em: https://www.ibge. gov.br/estatisticas/sociais/trabalho/9180-pesquisamensal-de-emprego.html?=\&t=series-historicas. Acesso em: 18 maio 2018.

IBOPE. 89\% dos manifestantes não se sentem representados por partidos. São Paulo, jun. 2013. Disponível em: http:/www.ibopeinteligencia.com/noticias-e-pesquisas/89-dos-manifestantes-naose-sentem-representados-por-partidos/. Acesso em: 18 maio 2018.

INEP. Censo da educação superior 2012: resumo técnico. Brasília: Inep, jul. 2014. Disponível em: http://download.inep.gov.br/download/superior/censo/2012/resumo_tecnico_censo_educacao_ superior_2012.pdf. Acesso em: 18 maio 2018.

JUDENSNAIDER, Elena; LIMA, Luciana; POMAR, Marcelo; ORTELLADO, Pablo. Vinte Centavos: a luta contra o aumento. São Paulo: Veneta, 2013.

LEANDRO, Melito. Com passagem de ônibus mais cara do país, SP será alvo de protestos nesta quinta. Portal do EBC, Brasília, DF, 5 jun. 2013. Disponível em: http://www.ebc.com.br/ cidadania/2013/06/com-passagem-de-onibus-mais-cara-do-pais-sp-sera-alvo-de-protestos-nestaquinta. Acesso em: 18 maio 2018.

LEMOS, Cláudia Regina Fonseca. A derrubada da PEC 37, as manifestações de junho de 2013 e as ações de comunicação do Ministério Público. In: CONGRESSO DA ASSOCIAÇÃO BRASILEIRA 
DE PESQUISADORES DE COMUNICAÇÃO E POLÍTICA - COMPOLÍTICA, 6., 2015, Rio de Janeiro. Anais [...]. Rio de Janeiro: [s. n.], 2015.

LOCATELLI, Piero. \#VemPraRua: as revoltas de junho pelo jovem repórter que recebeu passe livre para contar a história do movimento. São Paulo: Companhia das Letras, 2013.

LUHMANN, Niklas. A realidade dos meios de comunicação. 2. ed. Tradução de Ciro Marcondes Filho. São Paulo: Paulus, 2011a.

LUHMANN, Niklas. Ecological communication. Tradução de John Bednarz Jr. Cambridge: Polity Press, 1989.

LUHMANN, Niklas. Inclusión y exclusión. In: LUHMANN, Niklas. Complejidad y modernidad: de la unidad a la diferencia. Traducción de Josetxo Beriain y José María García Blanco. Madrid: Trotta, 1998. p. 167-195.

LUHMANN, Niklas. Introdução à teoria dos sistemas. Tradução de Ana Cristina Arantes Nasser. 3. ed. Petrópolis: Vozes, 2011 b.

LUHMANN, Niklas. Law as a social system. Oxford: Oxford University Press. May 2004.

LUHMANN, Niklas. Systemtheorie und protestbewegungen. In: HELLMANN, Kai-Uwe (ed.). Protest. Systemtheorie und soziale bewegungen. Frankfurt: Suhrkamp, 1996. p. 175-200.

MORA, Marcelo; VIANA, Julia Basso. Protesto contra tarifa tem confronto, depredações e presos em SP. G1, São Paulo, 11 jun. 2013. Disponível em: http://g1.globo.com/sao-paulo/noticia/2013/06/ protesto-contra-tarifa-tem-confronto-depredacoes-e-detidos-em-sp.html. Acesso em: 18 maio 2018. MOVIMENTO PASSE LIVRE. Carta de principios. São Paulo, jan. 2005. Disponível em: https:// saopaulo.mpl.org.br/apresentacao/carta-de-principios/.

NETTO, Andrei. Alckmin chama manifestantes de 'baderneiros' e 'vândalos'. O Estado de S. Paulo, São Paulo, 12 jun. 2013. Disponível em: https://sao-paulo.estadao.com.br/noticias/geral,alckminchama-manifestantes-de-baderneiros-e-vandalos,1041542. Acesso em: 18 maio 2018.

NOBRE, Marcos. Choque de democracia: razões da revolta. São Paulo: Companhia das Letras, 2013.

PURO vandalismo. O Estado de S. Paulo, São Paulo, 8 jun. 2013. Disponível em: https://opiniao. estadao.com.br/noticias/geral,puro-vandalismo-imp-,1040106. Acesso em: 18 maio 2018.

REJEIÇÃO da PEC 37, A. O Estado de S. Paulo, São Paulo, 30 jun. 2013. Disponível em: http:// opiniao.estadao.com.br/noticias/geral,a-rejeicao-da-pec-37-imp-,1048547. Acesso em: 18 maio 2018.

RODRIGUES, Artur. Haddad vai pedir ajuda de Dilma para baixar passagem. O Estado de S. Paulo, São Paulo, 8 jun. 2013. Disponível em: https://sao-paulo.estadao.com.br/noticias/geral,haddad-vaipedir-ajuda-de-dilma-para-baixar-passagem-imp-,1040168. Acesso em: 18 maio 2018. 
SP: promotor que incitou violência contra manifestantes é demitido do Mackenzie. Revista Fórum, Santos, 13 jun. 2013. Disponível em: https://revistaforum.com.br/noticias/sp-promotor-que-incitoua-violencia-contra-manifestantes-e-demitido-do-mackenzie/. Acesso em: 18 maio 2018.

TAFFARELLO, Rogério Fernando (coord.). As manifestações da sociedade civil e a repressão policial. Boletim IBCCRIM, São Paulo, n. 249, ago. 2013. Disponível em: http://www.ibccrim.org. br/boletim_editorial/290-249---agosto-2013. Acesso em: 18 maio 2018.

TARIFA ZERO. Movimento Passe Livre. [20--]. Disponível em: http://tarifazero.org/mpl/. Acesso em: 18 maio 2018.

VAINER, Carlos et al. Cidades rebeldes: Passe Livre e as manifestações que tomaram as ruas do Brasil. São Paulo: Boitempo, 2013.

VALENTE, Rubens; MAGALHÃES, João Carlos. 'Anonymous' lidera ativismo digital nos protestos, diz estudo. Folha de S. Paulo, São Paulo, 14 jul. 2013. Disponível em: https://www1. folha.uol.com.br/cotidiano/2013/07/1310892-anonymous-lidera-ativismo-digital-nos-protestosdiz-estudo.shtml. Acesso em: 18 maio 2018.

VEJA em quais cidades houve redução da tarifa do transporte em 2013. G1, São Paulo, 4 jul. 2013. Disponível em: http:/g1.globo.com/brasil/noticia/2013/07/veja-em-quais-cidades-houve-reducaoda-tarifa-do-transporte-em-2013.html. Acesso em: 18 maio 2018.

VILLAS BÔAS FILHO, Orlando. Teoria dos sistemas e o direito brasileiro. São Paulo: Saraiva, 2009.

WHIPPLE, Tom. Scientology: the Anonymous protestors. The Times, United Kingdom, 20 jun. 2008. Disponível em: https://www.thetimes.co.uk/article/scientology-the-anonymous-protestors5hpwnwh0m7j.

WORLD BANK. Poverty headcount ratio at $\$ 1.90$ a day (2011 PPP) (\% of population) - Brazil. Disponível em: https://data.worldbank.org/indicator/SI.POV.DDAY?end=2013\&locations=BR\&st art $=2011 \&$ view $=$ chart. Acesso em: 18 maio 2018. 